\title{
Techno-Eustress: The Impact of Perceived Usefulness and Perceived Ease of Use on the Perception of Work-Related Stressors
}

\author{
Julia Theresia Zielonka \\ Johannes Gutenberg-Universität Mainz \\ julia.zielonka@uni-mainz.de
}

\author{
Franz Rothlauf \\ Johannes Gutenberg-Universität Mainz \\ rothlauf@uni-mainz.de
}

\begin{abstract}
An extensive body of literature elaborates on the negative side of technostress. However, appraising stressors as challenges rather than as threats evidently leads to positive perceptions of stress, namely eustress. We derive from the person-environment fit model that the higher the acceptance of information and communication technologies is, the higher is the perception of eustress. As perceived usefulness and perceived ease of use are proven antecedents of technology acceptance, we study how these two technology beliefs affect the perception of challenge stressors and how the challenge stressors influence the psychological response in terms of perceived eustress. We collected data from 168 employees in a web-based survey and used structural equation modeling. The results support our propositions and confirm that perceived usefulness and perceived ease of use are significant determinants of work-related challenge stressors enhancing the perception of eustress.
\end{abstract}

\section{Introduction}

Information and communication technologies (ICT) have been pervading our lives for decades. Whereas people in their private lives are still free to choose which ICT they want to adopt and to what extent, employees usually do not have the choice of ICT adoption, may it be due to explicit job requirements or due to implicit norms at work [10]. ICT in the professional environment are intended to support us at work and improve our performance. With the introduction of ICT in the professional environment, however, also negative aspects emerged, such as the inability to effectively use offered technological resources or the general resistance to use ICT resulting in the perception of stress by the users [7]. These phenomena opened up a new area of interdisciplinary research in the field of psychology and information systems (IS) research, called technostress [9, 57].
Technostress denotes the stress perceived by individuals due to the use of ICT $[57,58]$. Studies showed that technostress may result in negative psychological and physiological outcomes [24], which in turn may cause job dissatisfaction, lower performance and productivity, decreased commitment, or burnout $[3,46,58]$. Therefore, it is also of interest to disclose the antecedents of the technostress process, called stressors.

Stressors, which are regularly interpreted in a negative sense, have been broadly studied, whereas the concept of eustress has received only little attention [57]. As one consequence of this, the term stress has become synonymous with the process of distress [20].

Although the field of psychology and organizational behavior differentiates between negative (distress) and positive stress (eustress), literature in the field of IS primarily focuses on the negative aspects of technology-induced stress [57]. Ayyagari et al. [3] developed and tested a technostress model where technostress referred to distress. Based on the personenvironment fit model, they argue that technology characteristics may create a misfit between environmental demands and the individual's values or capabilities. This misfit leads to the perception of distress in terms of feelings of strain [3]. Ayyagari et al. [3] proposed that technology characteristics are antecedents of stressors which in turn impact the perception of strain. They provided empirical evidence for the effect of technology characteristics on stressors leading to strain [3], but they did not differentiate between threat and challenge stressors [34, 53]. Challenge stressors induce the perception of eustress in form of feelings of achievement, motivation, and commitment [13, 34, 45, 53].

Since stressors can be interpreted either as a positive challenge or as a negative threat, we want to build upon the findings of Ayyagari et al. [3] and extend existing technostress research. In particular, we examine how technology influences the perception of challenge stressors. First, we draw from the challengehindrance framework of Cavanaugh et al. [13], which 
was developed in the field of organizational behavior and tested in work-related settings, to replicate the relationship between stressors and eustress. Second, according to the person-environment fit model, we argue that if ICT create a fit between environmental demands and individual's values and capabilities, the individual is more likely to appraise stressors as challenge rather than as threat. According to the Technology Acceptance Model (TAM), perceived usefulness (U) and perceived ease of use (EOU) are two important beliefs known to influence the attitude towards ICT and, thus, the acceptance of ICT $[18,60]$. We argue that $U$ und EOU have positive effects on the perception of stressors regarding the individual's appraisal of challenge stressors. Therefore, we integrate these two technology beliefs (U and EOU) and investigate their impact on the relationship between stressors and eustress perception.

To summarize, the aim of this research is to investigate the role of the most prevalent technology beliefs ( $U$ and EOU) in inducing perceived eustress in individuals. We theoretically develop and empirically study the effects of perceived usefulness and perceived ease of use on work-related challenge stressors and the impact on the perception of eustress.

In the subsequent sections, the research model is developed by reviewing relevant literature from the field of psychology and IS research. In order to test the derived hypotheses, we conducted a survey with 168 individuals. We perform a statistical analysis and present and discuss the results in sections 5 and 6 , respectively. The paper ends with concluding remarks.

\section{Theoretical background}

\subsection{Technology Acceptance Model}

The Technology Acceptance Model (TAM) [18] is one of the key models in IS research on ICT adoption and usage behavior. It has gained considerable prominence particularly due to its transferability to various contexts and its potential to study differences in the intention and continuance to use ICT [59, 60]. The driving forces of the behavioral usage intention are the beliefs of perceived usefulness (U) and perceived ease of use (EOU). $U$ is the extent to which an individual believes that the technology in question will enhance job performance. EOU is the degree to which an individual believes that the usage of that particular technology will be free of effort and, thus, easy to use [18]. Both constructs are determinants of technology acceptance and usage behavior [60]. In addition, EOU positively affects perceived usefulness [18].

\subsection{The transactional (techno-) stress model}

The Transactional Theory of Stress states that the perception of stress is an ongoing process of adaption based on transactions between the individual and his/her environment [21, 34]. This psychological perspective of stress perception acknowledges that external events do not directly lead to stress reactions but rather are negotiated within the individual [35, 54]. According to this model (Figure 1), external forces in terms of situations and demands impinge on the individual. The individual appraises these conditions as stressors. As a result of a primary appraisal, an individual classifies the environmental conditions either as threat or as challenge stressors. Depending on the classification, the individual reacts by evaluating its possible coping responses in form of a secondary appraisal. This results in affect or actions of the individual, which in turn leads to outcomes. The model views stress as an ongoing process of adaption based on interaction between an individual and his/her environment, where cognitive appraisals are the key to the individual's perception of stress. According to the model, environmental conditions and demands can be interpreted in either a positive, neutral, or negative way leading to different outcomes and, therefore, to different perceptions and levels of stress [21, 34, 35].

Selye [52] was the first to capture the ambivalence of stress perception and distinguished between distress and eustress. Distress refers to the process of appraising a situation as stressful in terms of strain when environmental demands exceed an individual's resources or capabilities and the individual assesses the situation as harmful [20]. Distress is known to evoke negative psychological (e.g. anxiety) and physiological outcomes (e.g. headaches) [24]. In contrast, eustress refers to the process of appraising stressors as challenging which motivates the individual to tackle the demands because of expecting that doing so leads to positive and affirmative outcomes, such as improved performance and productivity, increased efficiency or learning [11, 13, 45, 64].

Empirical research in work environments showed that managers often experience positive feelings in terms of achievement and fulfillment when being under pressure [43]. Cavanaugh et al. [13] also differentiates between challenge and hindrance stressors. They found

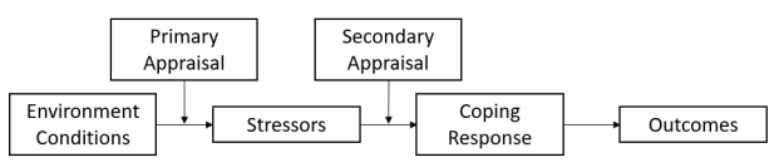

Figure 1. Transactional Stress Model $[34,57]$ 
that workload, job scope, responsibility, and pace of work are challenge stress factors that are positively related to job satisfaction and commitment and negatively related to job search. Thus, these challenge stressors can lead to beneficial perceptions of stress, namely eustress [13].

Stress in association with the usage of ICT is referred to as technostress [9]. The concept of technostress addresses contexts in which stress processes are initiated by the use of ICT [46, 57]. In the transactional stress model, ICT create demands which can exceed the individual's resources or capabilities. In this case, an individual appraises these demands as threat, and not as challenge. Technostress research extensively viewed technology as a threat with its negative outcomes [57]. Threat stressors include techno-overload, techno-invasion, technouncertainty, techno-complexity, and techno-insecurity [4, 17, 40, 55, 58]. Although psychology and organizational behavior research showed that not all stressors lead to the perception of distress but can also encourage in positive ways supporting the perception of eustress [53], research on how technology impacts the perception of eustress is limited [57].

\subsection{Person-Environment Fit Model}

The basic assumption of the person-environment (P-E) fit model is the concept of an equilibrium relationship between the individual and his/her environment [19]. The individual's environment provides supplies for fulfilling the individual's values or goals, but also places demands towards the individual. According to the P-E fit model, stress (in the form of strain) arises when there is a mismatch between the individual and his/her environment. This mismatch may occur due to two reasons. First, the individual has values and goals s/he is pursuing. If the environment does not provide the required supplies to fulfill the individual's desires and goals, the individual perceives this as gap, which leads to feelings of strain. Second, the environment places demands towards the individual. If the individual feels that these demands exceed his/her abilities, s/he evaluates this relationship as a mismatch, which in turn leads to feelings of strain. On the other hand, if there is congruence in environmental demands and the individual's goals, the individual appraises this situation as fit, which leads to positive feelings [19]. This model is widely used in stress research as it considers the appraisal process by which environmental situations are evaluated by the individual either as threat or as challenge stressor [16].

In our study, work-related stressors (e.g. workload) stand for environmental demands. Such stressors can create a misfit if the individual feels unable to satisfy these demands. However, we argue that ICT can also be perceived as useful (U) and easy to use (EOU), and therefore ICT can be seen as helpful for closing the gap between demands and capabilities. With the help of ICT, the individual feels that s/he can manage the environmental demands and, therefore, appraises the stressor as challenge rather than as threat.

Hence, we argue that perceived usefulness and perceived ease of use of ICT play a major role in the perception of stressors related to technology usage. We propose $\mathrm{U}$ and EOU as antecedents to challenge stressors, which in turn are predictors of perceived eustress in terms of feelings of achievements, motivation, and commitment (Figure 2).

\begin{tabular}{|c|c|c|}
\hline $\begin{array}{c}\text { Technology } \\
\text { Beliefs }\end{array}$ & $\begin{array}{c}\text { Challenge } \\
\text { Stressors }\end{array} \longrightarrow \begin{array}{c}\text { Perceived } \\
\text { Eustress }\end{array}$ \\
\hline
\end{tabular}

\section{Figure 2. General research model}

The following section derives the relationship between U, EOU, challenge stressors, and the perception of eustress in work settings.

\section{Hypotheses development}

According to the transactional stress model, stressors can be perceived either as challenge or as threat. If a user categorizes stressors as challenge, stress is perceived as motivating and encouraging, thus, in a positive way [53]. Consistent with research on stress in work settings, we identified four major challenge stressors: workload, job scope, responsibility, and pace of work [8, 13, 36, 37]. Podsakoff et al. [45] found evidence that these challenge stressors are positively associated with job satisfaction and organizational commitment which are also manifestations of perceived eustress [8, 13, 28]. Consequently, we posit the positive impact of the work-related challenge stressors on perceived eustress in form of job commitment, motivation, and satisfaction.

H1: Workload is positively related to perceived eustress.

H2: Job scope is positively related to perceived eustress.

H3: Responsibility is positively related to perceived eustress.

H4: Pace of work is positively related to perceived eustress.

ICT are ubiquitous and without alternatives in organizational life. Thus, it is of major importance to understand the effects of technology usage and demands on individuals. According to the technology acceptance model (TAM), technology acceptance and usage behavior are determined by the two key beliefs, 
$\mathrm{U}$ and EOU. Various studies already proved that EOU positively influences the perception of usefulness of ICT, because the easier a technology is to use, the more useful that technology is to the individual [18].

H5: Perceived ease of use is positively related to perceived usefulness.

Workload is defined as the amount or volume of work an individual is expected to do [12]. This is not to be confounded with workoverload, where the amount of work is too large and people experience negative outcomes and feelings, such as strain. Thus, the construct of workload captures the individual's positive perceptions of the amount of work. Consequently, respondents perceive a higher workload as positive. Studies showed that challenging workers with workload expectations can stimulate the individual to work with optimal performance [56]. Providing employees with ICT that help to accomplish the expected volume of work will benefit the perception of workload since productivity increases [2, 30, 31]. Furthermore, technology can provide more flexibility to work where and when it suits best. This also enhances the feeling of satisfaction and increases efficiency [13]. Thus, we argue that the more useful a technology is to tackle the requested amount of work, the more positive is the perception of the challenge stressor workload. Also, the easier that particular technology is to handle, the better the technology supports the individual in accomplishing his/her tasks.

H6a: Perceived ease of use is positively related to workload.

H6b: Perceived usefulness is positively related to workload.

Job scope refers to the variety and range of demands towards the individual. Technology is known to support and even augment the individual's capabilities [32, 41]. Studies revealed that technology enhances organizational innovation due to uncovering new use cases for existing technology applications [25, 31] which may result in excitement and feelings of achievement $[5,6]$. Offering employees ICT that are useful to accomplish job demands affects the perception of the challenge stressor job scope [63]. We argue that the more useful an individual perceives the technology in use, the more positive is the perception of job scope. In addition, the easier the supportive technology is to use, the easier it is for the individual to meet the job demands towards him/her, thus, leading to a more positive perception of job scope.

H7a: Perceived ease of use is positively related to job scope.

H7b: Perceived usefulness is positively related to job scope.

Job responsibility encompasses the level of accountability assigned to an individual. Having responsibility also means having control over something or others. This entails the necessity of decision making. ICT are able to provide information based on data which would not have been available without technology [63]. Moreover, information can be analyzed at a more complex level with the help of ICT. Previous research found that ICT can help individuals to make better decisions [39]. Thus, employees do not feel overwhelmed by the responsibility they have but rather challenged and motivated to control their environment with the help of ICT.

H8a: Perceived ease of use is positively related to responsibility.

H8b: Perceived usefulness is positively related to responsibility.

Pace of work is a quantitative productivity measure that measures how much work is done in a given time. Various studies showed that time pressure up to a certain degree can motivate employees to work faster. Providing employees with relevant and useful ICT that support employees in accomplishing the required work in the given time frame improves work productivity, achievement, and satisfaction [63]. Thus, the more useful and the easier to use a technology is, the more encouraging the pace of work is perceived.

H9a: Perceived ease of use is positively related to pace of work.

H9b: Perceived usefulness is positively related to pace of work.

The use of ICT in organizations intends to make our professional lives easier, provide flexibility, increase performance, and improve quality of work. Thus, technology enables individuals to improve performance and, hence, leads to feelings of motivation and achievement [13, 62, 63]. The easier a certain technology is to use and the more useful it is perceived to be for the individual, the higher is the acceptance and actual usage of that technology [18]. Using technology with the knowledge that it enables us to improve our performance, and achieve better results, leads to feelings of motivation, achievement, and commitment, in short eustress.

H1Oa: Perceived ease of use is positively related to perceived eustress.

H1Ob: Perceived usefulness is positively related to perceived eustress.

\section{Method}

The objective of this paper is to clarify the effects of perceived usefulness and perceived ease of use on challenge stressors in work environments in order to develop a model of techno-eustress. As we analyze the causal relationships between the aforementioned variables, a field study was conducted for data 
collection. We use structural equation modeling for the statistical analysis.

\subsection{Data collection}

We collected the data with an online survey. We invited friends, colleagues, and acquaintances via email to participate in our survey and to forward the invitation to their friends and colleagues. The target population for this study was not limited to any specific profession (e.g. librarians, nurses, IT professionals), as we intend to analyze and understand the impact of ICT characteristics on challenge stressors in general work settings. However, we controlled the sample for the degree of technology usage at work, as the effects of technologies are a function of the usage extent. We acquired 168 respondents, out of which 10 were eliminated due to not meeting the screening measure of at least four hours of work per day with ICT. In addition, a list with common ICT was provided and participants were asked to indicate which kind of hardware and software they regularly use at work (multiple answers were possible; see Table 1).

\subsection{Measures}

We adapted existing validated scales to measure the constructs. The reflective items for perceived usefulness and perceived ease of use are taken from TAM studies $[18,61]$. The measures of the challenge stressors workload, pace of work, job scope, and job responsibility were taken and adapted from Cavanaugh et al. [13], Lepine et al. [36], and Podsakoff et al. [45]. For the measure of eustress in the context of work, we selected and adapted items from O'Sullivan [42] and Schaufeli et al. [51] as we infer that engagement, dedication, motivation, and positive feelings towards work capture eustress in the work environment $[8,13]$. For the validation of all constructs, we performed a factor analysis.

All items are measured on a seven point LikertScale, where 1 stands for "I do not agree at all" and 7 indicates "I totally agree". For example, the challenge stressor workload (which should not be confused with workoverload) has a high score if workload is perceived as positive by the respondents, whereas low points in workload rather describe the feeling of workoverload, when people feel overwhelmed by the required amount of work and are incapable handling it [3].

In addition, we collected control variables, such as gender, age, work experience in years, average usage of ICT in hours per day at work, average usage of ICT in hours per day in private life, and number of ICT used (e.g. Smartphone, Tablet PC etc.).

\section{Table 1. Sample characteristics}

\begin{tabular}{|c|c|c|c|}
\hline $\begin{array}{l}\text { Demo- } \\
\text { graphics }\end{array}$ & & $\begin{array}{c}\text { Absolute } \\
\text { value }\end{array}$ & Percent \\
\hline \multirow{2}{*}{ Gender } & female & 74 & 46.8 \\
\hline & male & 84 & 53.2 \\
\hline \multirow{4}{*}{$\begin{array}{l}\text { Age in } \\
\text { years }\end{array}$} & $20-30$ & 70 & 44.3 \\
\hline & $31-40$ & 49 & 31.0 \\
\hline & $41-50$ & 19 & 12.0 \\
\hline & $>=51$ & 20 & 12.7 \\
\hline \multirow{5}{*}{$\begin{array}{c}\text { Annual } \\
\text { income in } \\
\text { Euro }\end{array}$} & $<30.000 €$ & 27 & 17.1 \\
\hline & $30.000 €-50.000 €$ & 27 & 17.1 \\
\hline & $50.000 €-70.000 €$ & 46 & 29.1 \\
\hline & $70.000 €-100.000 €$ & 36 & 22.8 \\
\hline & $>100.000 €$ & 22 & 13.9 \\
\hline \multirow{4}{*}{$\begin{array}{c}\text { Work } \\
\text { experience } \\
\text { in years }\end{array}$} & $1-5$ & 72 & 45.6 \\
\hline & $6-15$ & 43 & 27.2 \\
\hline & $16-25$ & 21 & 13.3 \\
\hline & $>=26$ & 22 & 13.9 \\
\hline \multirow{3}{*}{$\begin{array}{c}\text { ICT usage } \\
\text { at work } \\
\text { (hours per } \\
\text { day) }\end{array}$} & $4-6$ & 33 & 20.9 \\
\hline & $6-8$ & 82 & 51.9 \\
\hline & $>8$ & 43 & 27.2 \\
\hline \multirow{5}{*}{$\begin{array}{c}\text { Private } \\
\text { usage of } \\
\text { ICT } \\
\text { (hours per } \\
\text { day) }\end{array}$} & $<2$ & 29 & 18.4 \\
\hline & $2-4$ & 91 & 57.6 \\
\hline & $4-6$ & 27 & 17.1 \\
\hline & $6-8$ & 8 & 5.1 \\
\hline & $>8$ & 3 & 1.9 \\
\hline \multirow{8}{*}{$\begin{array}{c}\text { ICT } \\
\text { devices } \\
\text { used at } \\
\text { work }\end{array}$} & Laptop / Computer & 155 & 98.1 \\
\hline & Tablet PC & 27 & 17.1 \\
\hline & Smartphone & 115 & 72.8 \\
\hline & Telephone & 126 & 79.7 \\
\hline & E-Mail Programs & 146 & 92.4 \\
\hline & $\begin{array}{l}\text { Communication } \\
\text { Applications }\end{array}$ & 105 & 66.5 \\
\hline & \begin{tabular}{|l|} 
Collaboration \\
Platforms \\
\end{tabular} & 100 & 63.3 \\
\hline & Other & 12 & 7.6 \\
\hline
\end{tabular}

\section{Data analysis}

For data analysis and testing the proposed hypotheses, we applied structural equation modeling (SEM). Partial least squares (PLS) SEM was used as it is a powerful technique with the advantage that it does not assume any specific distribution [14, 15]. Furthermore, the context of our study is rather 
explorative than confirmative since techno-eustress is a rather underexplored research area [57]. In such a context, PLS SEM is the method of choice [15].

In total, we received 158 fully filled questionnaires, which meet the set requirements (see section 4.1). Out of the 158 individuals, $46.8 \%$ were female and $53.2 \%$ were male ( $0 \%$ other). Table 1 shows the descriptive data collected.

\subsection{Measurement model}

The measured items are indicators for the latent unobservable variables that represent the constructs. Therefore, we test the reliability and validity of the constructed measures [48]. Table 2 indicates that the average variance extracted (AVE) for all constructs exceeds the necessary threshold of 0.5 confirming the validity of our constructs [22]. To ensure the reliability of the measures, we calculated the composite reliability and Cronbach's Alpha. All values exceed the required threshold of 0.6 and, therefore, confirm the reliability of our constructs measurement. Table 3 reports the Fornell-Larcker criterion test results, which measure the discriminant validity. All measures meet the required criteria [22].

Table 2. Reliability statistics of the measurement model

\begin{tabular}{|c|c|c|c|}
\hline & $\begin{array}{c}\text { Average Variance } \\
\text { Extracted }\end{array}$ & $\begin{array}{c}\text { Cronbach's } \\
\text { Alpha }\end{array}$ & $\begin{array}{c}\text { Composite } \\
\text { Reliability }\end{array}$ \\
\hline EOU & 0.697 & 0.891 & 0.920 \\
\hline U & 0.716 & 0.900 & 0.926 \\
\hline WL & 0.666 & 0.876 & 0.909 \\
\hline JS & 0.673 & 0.875 & 0.910 \\
\hline RE & 0.520 & 0.771 & 0.844 \\
\hline PW & 0.554 & 0.716 & 0.828 \\
\hline EU & 0.526 & 0.813 & 0.867 \\
\hline
\end{tabular}

Table 3. Fornell-Larcker criterion test results

\begin{tabular}{|c|c|c|c|c|c|c|c|}
\hline & EOU & U & WL & JS & RE & PW & EU \\
\hline EOU & $\mathbf{0 . 8 3 5}$ & & & & & & \\
\hline U & 0.420 & $\mathbf{0 . 8 4 6}$ & & & & & \\
\hline WL & 0.217 & 0.209 & $\mathbf{0 . 8 1 6}$ & & & & \\
\hline JS & 0.300 & 0.184 & 0.692 & $\mathbf{0 . 8 2 0}$ & & & \\
\hline RE & 0.241 & 0.205 & 0.476 & 0.586 & $\mathbf{0 . 7 2 1}$ & & \\
\hline PW & 0.325 & 0.313 & 0.653 & 0.562 & 0.470 & $\mathbf{0 . 7 4 4}$ & \\
\hline EU & 0.394 & 0.409 & 0.559 & 0.645 & 0.446 & 0.487 & $\mathbf{0 . 7 2 5}$ \\
\hline
\end{tabular}

\subsection{Structural model}

We test the structural model for multi-collinearity based on the variance inflation factor (VIF). As shown in table 4, all VIF values are below the threshold of 3 . This indicates no multi-collinearity between the constructs $[29,50]$.
The total effects are calculated using PLS SEM and tested for significance. Figure 3 shows the model with its path coefficients and significance levels for the postulated hypotheses. According to the test results, the challenge stressors workload $(\mathrm{H} 1)$ and job scope $(\mathrm{H} 2)$ are significant predictors of eustress while the hypotheses that responsibility (H3) and pace of work (H4) contribute to eustress need to be rejected. While perceived ease of use is a significant factor positively influencing all of the four tested challenge stressors, workload (H6a), job scope $(\mathrm{H} 7 \mathrm{a})$, responsibility $(\mathrm{H} 8 \mathrm{a})$, and pace of work (H9a), perceived usefulness only affects the positive perception of workload (H6b) and pace of work (H9b). Contrary to $\mathrm{H} 7 \mathrm{~b}$ and $\mathrm{H} 8 \mathrm{~b}$, perceived usefulness is not a significant determinant of job scope and responsibility respectively. As hypothesized, perceived ease of use (H10a) and perceived usefulness $(\mathrm{H} 10 \mathrm{~b})$ are direct determinants of the perception of eustress.

Table 4. Variance inflation factors

\begin{tabular}{|c|c|c|c|c|c|c|}
\hline & EU & U & WL & JS & RE & PW \\
\hline EOU & 1.323 & 1.000 & 1.215 & 1.215 & 1.215 & 1.215 \\
\hline $\mathbf{U}$ & 1.277 & & 1.215 & 1.215 & 1.215 & 1.215 \\
\hline WL & 2.407 & & & & & \\
\hline JS & 2.385 & & & & & \\
\hline RE & 1.604 & & & & & \\
\hline PW & 2.005 & & & & & \\
\hline
\end{tabular}

\section{Discussion}

The analysis of the proposed structural model indicates that $53 \%\left(\mathrm{R}^{2}=0.531\right)$ of the variance of eustress is explained by the proposed model. The strongest direct effect on eustress perception is contributed by $U$ with a path coefficient of 0.235 . EOU is also positively related to eustress with a coefficient of 0.121. These findings are in line with our hypotheses H10a and H10b. Using ICT that is perceived as useful increases feelings of motivation, achievement, and commitment as it improves performance and quality of work $[13,62,63]$. We find that ICT need to be easy to use as this also proves to be a strong determinant of the perception of challenge stressors. This is consistent with findings of previous research in techno-distress, where complexity was a significant factor impacting strain and leading to distress, which negatively affects motivation and commitment $[3,11]$.

The strongest contributor of challenge stressors to eustress is job scope. This is in line with existing research supporting the impact of job scope on job 


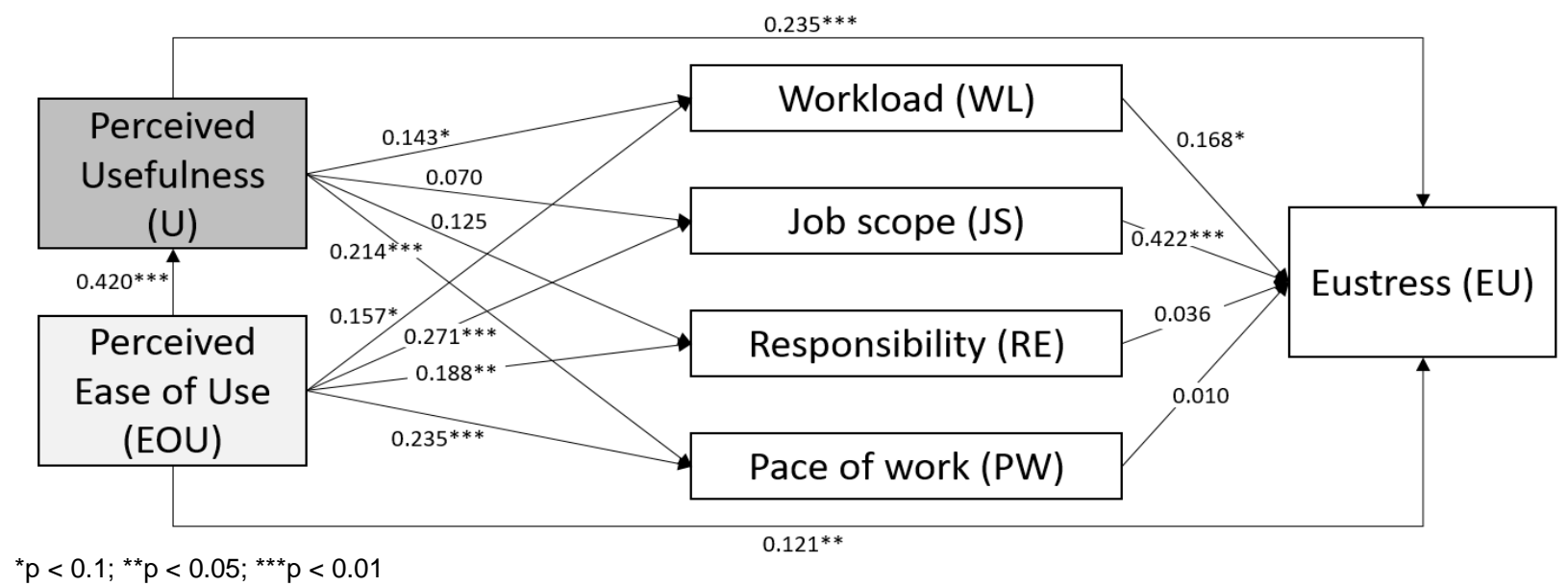

Figure 3. Structural model with results

commitment and satisfaction [33,47]. According to literature on job design, job scope is higher if the skills needed to fulfill the job requirements have a higher variety [27]. High job scopes are often identified as complex and challenging [23, 44] and are proved to have a positive impact on job commitment and satisfaction [33].

Our results provide support for the proposition that technology beliefs about the ease of use positively impact the perception of the challenge stressor job scope. The easier to use a technology is perceived by the individual, the more s/he feels supported and able to tackle the demands which result from the complexity of his/her job scope. Feeling able to accomplish complex and challenging job requirements provides feelings of achievement and joy, which are outcomes of perceived eustress.

Contrary to our expectations and proved relationships in previous studies [3, 13, 45], responsibility and pace of work do not significantly relate to the perception of eustress in our study. This might be due to the general ambiguity of the two stressors. Responsibility entails control and decision making, which is known to increase job satisfaction and commitment [26, 49]. However, control and decision making can also lead to feelings of pressure and strain. Still, easy-to-use technologies that support the individual in his/her decision making process and in exerting control increase the positive perception of the challenge stressor responsibility (0.188). Interestingly, the relationship between $\mathrm{U}$ and the stressor responsibility is not significant. Also, pace of work is only perceived challenging up to a certain degree. If employees find themselves overloaded with work, which needs to be done in a specific time, they might perceive pace of work not as challenging but rather as threatening [28]. Nevertheless, U and EOU have a significant positive impact on the perception of the challenge stressor pace of work. This supports our hypothesis that technology is perceived as helpful for managing high workload which needs to be done in a specific time.

Recently, Zhao et al. [64] found that problem and emotion focused coping strategies are mediators of the relationship between the appraisal of a stressor as a challenge or a hindrance and ICT-enabled productivity. These findings might explain why some hypothesized relationships could not be validated in our studies. However, it needs to be noted that our underlying research model differs from studies where ICT and their artefacts are stressors themselves [11, 64]. In contrast, our research model suggests and proves that ICT characteristics, specifically perceived usefulness and perceived ease of use, affect the perception of work-related stressors which in turn result in the perception of eustress [3].

To conclude, the results support our general research model (Figure 2) and the analysis provides evidence that $U$ and EOU are significant determinants of work-related challenge stressors and eustress (Figure 3). Thus, the usability aspects addressed in this paper are of high relevance when designing and introducing ICT in the working environment.

\section{Implications, limitations, and outlook}

This study uncovers the role of technology beliefs, perceived usefulness and perceived ease of use, for inducing eustress in individuals. We propose the two beliefs as antecedents to work-related challenge stressors (workload, job scope, job responsibility, and pace of work), which in turn are predictors of eustress expressed as motivation, achievement, and commitment. In order to test our derived hypotheses, we collected data from 168 employees on their perception of usefulness and ease of use of ICT, workrelated stressors, and eustress. The analysis supports 
the majority of our postulated propositions. In particular, we find that perceived ease of use and perceived usefulness of ICT significantly impact the perception of challenge stressors, which in turn induces feelings of job commitment and motivation, in short eustress. We also find strong direct effects of perceived ease of use and perceived usefulness on the perception of eustress.

This article is the first to theoretically derive and empirically test the relationship between $U$ and EOU and work-related challenge stressors under the conceptual framework of the eustress process. Thus, our study advances the understanding of the explicit role and impact of $\mathrm{U}$ and EOU in the ICT related eustress process.

Our model also explains why work-related eustress can be experienced differentially by the individual, depending on the extent of the perception of how useful and easy to use ICT are. Thus, increasing the usefulness of ICT and designing easy-to-use ICT fosters the perception of work-related eustress, which is a desirable outcome for practitioners, as eustress is known to enhance productivity [64].

Although this study is a fruitful extension of technostress research, it also comes along with some limitations. First, this study used self-reported measures of the construct variables. Despite the advantages of online panels (e.g. regarding anonymity, reaching participants with various backgrounds, selfreports to capture individual perceptions [17, 38]), we suggest applying a multi-method approach for further studies. We assume that the combination of selfreported and physiological measurements would be enriching in order to capture all aspects of the technostress process. Second, this study focused on four work-related challenge stressors identified by previous research $[13,45]$. It needs to be examined whether there are further challenge stressors, which explicitly emerge from the usage of ICT, inducing eustress in individuals. Finally, we explicitly investigated the impact of two major beliefs about technology which are proved to be the universal determinants of technology acceptance and usage behavior $[1,18]$. It is of interest to elucidate if there are more technology-related determinants of the perception of eustress.

\section{References}

[1] Adams, D.A., R.R. Nelson, and P.A. Todd, "Perceived usefulness, ease of use, and usage of information technology: A replication", MIS Quarterly: Management Information Systems 16(2), 1992, pp. 227-247.

[2] Aral, S., E. Brynjolfsson, and M. Van Alstyne,
"Information, technology, and information worker productivity", Information Systems Research 23(3 PART 2), 2012, pp. 849-867.

[3] Ayyagari, R., V. Grover, and R. Purvis, "Technostress: Technological antecedents and implications", MIS Quarterly: Management Information Systems 35(4), 2011, pp. 831-858.

[4] Barber, L.K., and A.M. Santuzzi, "Please respond ASAP: Workplace telepressure and employee recovery.", Journal of Occupational Health Psychology 20(2), 2015, pp. 172-189.

[5] Beaudry, and Pinsonneault, "Understanding User Responses to Information Technology: A Coping Model of User Adaptation", MIS Quarterly 29(3), 2005, pp. 493-524.

[6] Beaudry, and Pinsonneault, "The Other Side of Acceptance: Studying the Direct and Indirect Effects of Emotions on Information Technology Use", MIS Quarterly 34(4), 2010, pp. 689-710.

[7] Bichteler, J., "Human Aspects of High Tech in Special Libraries.”, Special Libraries 77(3), 1986, pp. 121-28.

[8] Boswell, W.R., J.B. Olson-Buchanan, and M.A. LePine, "Relations between stress and work outcomes: The role of the felt challenge, job control, and psychological strain", Journal of Vocational Behavior 64(1), 2004, pp. 165-181.

[9] Brod, C., "Managing technostress: optimizing the use of computer technology.", The Personnel journal 61(10), 1982, pp. 753-7.

[10] Brown, R., J. Duck, and N. Jimmieson, "E-mail in the workplace: The role of stress appraisals and normative response pressure in the relationship between e-mail stressors and employee strain.", International Journal of Stress Management 21(4), 2014, pp. 325-347.

[11] Califf, C.B., S. Sarker, and S. Sarker, "The Bright and Dark Sides of Technostress: A Mixed-Methods

Study Involving Healthcare IT.", MIS Quarterly 44(2), 2020, pp. 809-856.

[12] Campbell, T.S., J.A. Johnson, K.A. Zernicke, et al., "Workload", In Encyclopedia of Behavioral Medicine. Springer New York, 2013, 2068-2069.

[13] Cavanaugh, M.A., W.R. Boswell, M. V. Roehling, and J.W. Boudreau, "An empirical examination of selfreported work stress among U.S. managers", Journal of Applied Psychology 85(1), 2000, pp. 65-74.

[14] Chin, W.W., "The partial least squares approach for structural equation modeling", In Modern Methods for Business Research. Erlbaum Associates, London, UK, 1998, 295-336.

[15] Chin, W.W., and P.R. Newsted, "Structural equation modeling analysis with small samples using partial least squares", In Statistical Methods for Small Sample Research. Hoyle, Thousand Oaks, 1999, 307- 
342.

[16] Cooper, C.L., P.J. Dewe, and M.P. O'Driscoll, Organizational Stress: A review and critique of theory, research, and applications, Sage PublicationsSage CA: Thousand Oaks, CA, 2001.

[17] D'Arcy, J., T. Herath, and M.K. Shoss, "Understanding Employee Responses to Stressful Information Security Requirements: A Coping Perspective", Journal of Management Information Systems 31(2), 2014, pp. 285-318.

[18] Davis, F.D., "Perceived Usefulness, Perceived Ease of Use, and User Acceptance of Information Technology", MIS Quarterly 13(3), 1989, pp. 319-339. [19] Edwards, J.R., "An Examination Of Competing Versions Of The Person-Environment Fit Approach To Stress", Academy of Management Journal 39(2), 1996, pp. 292-339.

[20] Le Fevre, M., J. Matheny, and G.S. Kolt, "Eustress, distress, and interpretation in occupational stress", Journal of Managerial Psychology 18, 2003, 726-744.

[21] Folkman, S., R.S. Lazarus, C. Dunkel-Schetter, A. DeLongis, and R.J. Gruen, "Dynamics of a stressful encounter: Cognitive appraisal, coping, and encounter outcomes.", Journal of Personality and Social Psychology 50(5), 1986, pp. 992-1003.

[22] Fornell, C., and D.F. Larcker, "Evaluating Structural Equation Models with Unobservable Variables and Measurement Error", Journal of Marketing Research 18(1), 1981, pp. 39-50.

[23] Fried, Y., and G.R. Ferris, "The Validity of the Job Characteristics Model: A Review and Meta-Analysis", Personnel Psychology 40(2), 1987, pp. 287-322.

[24] Galluch, P., V. Grover, and J. Thatcher, "Interrupting the Workplace: Examining Stressors in an Information Technology Context", Journal of the Association for Information Systems 16(1), 2015, pp. $1-47$.

[25] Garcia-Vega, M., "Does technological diversification promote innovation?: An empirical analysis for European firms", Research Policy 35(2), 2006, pp. 230-246.

[26] Greenberger, D.B., S. Strasser, L.L. Cummings, and R.B. Dunham, "The impact of personal control on performance and satisfaction", Organizational Behavior and Human Decision Processes 43(1), 1989, pp. 29-51.

[27] Hackman, J.R., "Work redesign and motivation", Professional Psychology: Research and Practice 11(3), 1980, pp. 445-455.

[28] Hargrove, M.B., W.S. Becker, and D.F. Hargrove, "The HRD Eustress Model", Human Resource Development Review 14(3), 2015, pp. 279-298. [29] Jagpal, H.S., "Multicollinearity in Structural
Equation Models with Unobservable Variables", Journal of Marketing Research 19(4), 1982, pp. 431439.

[30] Jain, V., and S. Kanungo, "Beyond perceptions and usage: Impact of nature of information systems use on information system-enabled productivity", International Journal of Human-Computer Interaction 19(1), 2005, pp. 113-136.

[31] Jasperson, J., P.E. Carter, and R.W. Zmud, "A comprehensive conceptualization of post-adoptive behaviors associated with information technology enabled work systems", MIS Quarterly 29(3), 2005, pp. 525-557.

[32] Jelinek, R., M. Ahearne, J. Mathieu, and N. Schillewaert, "A longitudinal examination of individual, organizational, and contextual factors on sales technology adoption and job performance", Journal of Marketing Theory and Practice 14(1), 2006, pp. 7-23.

[33] Lapointe, É., and C. Vandenberghe, "Supervisory mentoring and employee affective commitment and turnover: The critical role of contextual factors", Journal of Vocational Behavior 98, 2017, pp. 98-107. [34] Lazarus, R.S., and S. Folkman, Stress, appraisal, and coping, Springer publishing company, New York, NY, USA, 1984.

[35] Lazarus, R.S., and S. Folkman, "Cognitive Theories of Stress and the Issue of Circularity", In Dynamics of Stress. Springer US, Boston, MA, 1986, 63-80.

[36] Lepine, J.A., M.A. Lepine, and C.L. Jackson, "Challenge and Hindrance Stress: Relationships with exhaustion, motivation to learn, and learning performance", Journal of Applied Psychology 89(5), 2004, pp. 883-891.

[37] LePine, J.A., N.P. Podsakoff, and M.A. LePine, "A meta-analytic test of the challenge Stressorhindrance stressor framework: An explanation for inconsistent relationships among Stressors and performance", Academy of Management Journal 48(5), 2005, pp. 764-775.

[38] Lowry, P.B., J. Zhang, C. Wang, and M. Siponen, "Why Do Adults Engage in Cyberbullying on Social Media? An Integration of Online Disinhibition and Deindividuation Effects with the Social Structure and Social Learning Model", Information Systems Research 27(4), 2016, pp. 962-986.

[39] Magnavita, J.J., F. Caspar, T. Berger, and L. Frei, "Using technology to enhance decision making.", In Clinical decision making in mental health practice. American Psychological Association, 2015, 147-174. [40] Maier, C., S. Laumer, C. Weinert, and T. Weitzel, "The effects of technostress and switching stress on discontinued use of social networking services: a study of Facebook use", Information Systems Journal 25(3), 
2015, pp. 275-308.

[41] Napoleon, K., and C. Gaimon, "The Creation of Output and Quality in Services: A Framework to Analyze Information Technology-Worker Systems", Production and Operations Management 13(3), 2009, pp. 245-259.

[42] O’Sullivan, G., "The Relationship between Hope, Eustress, Self-Efficacy, and Life Satisfaction among Undergraduates", Social Indicators Research 101(1), 2011, pp. 155-172.

[43] Ohlott, P.J., M.N. Ruderman, and C.D. McCauley, 'Gender Differences in Managers' Developmental Job Experiences", Academy of Management Journal 37(1), 1994, pp. 46-67.

[44] Parker, S.K., "Beyond Motivation: Job and Work Design for Development, Health, Ambidexterity, and More", Annual Review of Psychology 65(1), 2014, pp. 661-691.

[45] Podsakoff, N.P., J.A. Lepine, and M.A. Lepine, "Differential challenge stressor-hindrance stressor relationships with job attitudes, turnover intentions, turnover, and withdrawal behavior: A meta-analysis", Journal of Applied Psychology 92(2), 2007, pp. 438454.

[46] Ragu-Nathan, T.S., M. Tarafdar, B.S. RaguNathan, and Q. Tu, "The Consequences of Technostress for End Users in Organizations: Conceptual Development and Empirical Validation", Information Systems Research 19(4), 2008, pp. 417433.

[47] Raja, U., and G. Johns, "The joint effects of personality and job scope on in-role performance, citizenship behaviors, and creativity", Human Relations 63(7), 2010, pp. 981-1005.

[48] Roldán, J.L., and M.J. Sánchez-Franco, "Variance-based structural equation modeling: Guidelines for using partial least squares in information systems research", In Research Methodologies, Innovations and Philosophies in Software Systems Engineering and Information Systems. IGI Global, 2012, 193-221.

[49] Rose, E., and G. Wright, "Satisfaction and dimensions of control among call centre customer service representatives", International Journal of Human Resource Management 16(1), 2005, pp. 136160.

[50] Salmerón Gómez, R., J. García Pérez, M.D.M. López Martín, and C.G. García, "Collinearity diagnostic applied in ridge estimation through the variance inflation factor", Journal of Applied Statistics 43(10), 2016, pp. 1831-1849.

[51] Schaufeli, W.B., M. Salanova, V. GonzálezRomá, and A.B. Bakker, "The Measurement of Engagement and Burnout: A Two Sample Confirmatory Factor Analytic Approach", Journal of
Happiness Studies 3, 2002, pp. 71-92.

[52] Selye, H., The stress of life, McGraw-Hill, New York, NY, USA, 1956.

[53] Selye, H., "Stress without Distress BT Psychopathology of Human Adaptation", In G. Serban, ed., Serban G. (eds). Psychopathology of Human Adaptation. Springer US, 1976, 137-146.

[54] Sherman, E., A. Mathur, and R.B. Smith, "Store environment and consumer purchase behavior: Mediating role of consumer emotions", Psychology \& Marketing 14(4), 1997, pp. 361-378.

[55] Sprigg, C.A., and P.R. Jackson, "Call centers as lean service environments: Job-related strain and the mediating role of work design.", Journal of Occupational Health Psychology 11(2), 2006, pp. 197212.

[56] Tan, T.F., and S. Netessine, "When does the devil make work? An empirical study of the impact of workload on worker productivity", Management Science 60(6), 2014, pp. 1574-1593.

[57] Tarafdar, M., C.L. Cooper, and J. Stich, "The technostress trifecta - techno eustress, techno distress and design: Theoretical directions and an agenda for research", Information Systems Journal 29(1), 2019, pp. 6-42.

[58] Tarafdar, M., Q. Tu, B.S. Ragu-Nathan, and T.S. Ragu-Nathan, "The Impact of Technostress on Role Stress and Productivity", Journal of Management Information Systems 24(1), 2007, pp. 301-328. [59] Venkatesh, V., "Determinants of Perceived Ease of Use: Integrating Control, Intrinsic Motivation, and Emotion into the Technology Acceptance Model", Information Systems Research 11(4), 2000, pp. 342365.

[60] Venkatesh, V., and F.D. Davis, "A Theoretical Extension of the Technology Acceptance Model: Four Longitudinal Field Studies", Management Science 46(2), 2000, pp. 186-204.

[61] Venkatesh, V., M.G. Morris, and P.L. Ackerman, "A Longitudinal Field Investigation of Gender Differences in Individual Technology Adoption Decision-Making Processes", Organizational Behavior and Human Decision Processes 83(1), 2000, pp. 3360.

[62] Wajcman, J., and E. Rose, "Constant Connectivity: Rethinking Interruptions at Work", Organization Studies 32(7), 2011, pp. 941-961. [63] Wu, L., "Social network effects on productivity and job security: Evidence from the adoption of a social networking tool", Information Systems Research 24(1), 2013, pp. 30-51.

[64] Zhao, X., Q. Xia, and W. Huang, "Impact of technostress on productivity from the theoretical perspective of appraisal and coping processes", Information and Management, 2020, pp. 103265. 